This PDF is a selection from a published volume from the National Bureau of Economic Research

Volume Title: Price Index Concepts and Measurement

Volume Author/Editor: W. Erwin Diewert, John S. Greenlees and Charles R. Hulten, editors

Volume Publisher: University of Chicago Press

Volume ISBN: 0-226-14855-6

Volume URL: http://www.nber.org/books/diew08-1

Conference Date: June 28-29, 2004

Publication Date: December 2009

Chapter Title: Introduction: What Are the Issues?

Chapter Author: W. Erwin Diewert, John Greenlees, Charles R. Hulten

Chapter URL: http://www.nber.org/chapters/c5067

Chapter pages in book: $(1-16)$ 


\title{
Introduction What are the Issues?
}

\author{
W. Erwin Diewert, John Greenlees, and Charles Hulten
}

The report of the National Research Council (NRC) Panel on Conceptual, Measurement, and Other Statistical Issues in Developing Cost-of-Living Indexes, under the chairmanship of Charles Schultze, addresses virtually all the fundamental issues in consumer price measurement that have long been the subject of debate. ${ }^{1}$ Underlying many of these issues is the concept of the Cost-of-Living Index or COLI, or other methodological alternatives to it. The role of the COLI as the methodological foundation for a Consumer Price Index (CPI) was examined and advocated in two previous reviews of the CPI, the 1961 Stigler Report ${ }^{2}$ and the 1996 Boskin Report. $^{3}$ The NRC panel took a different, and somewhat controversial, position by suggesting a Cost-of-Goods Index (COGI) as a potential alternative theoretical foundation for the CPI. This COGI methodology would differ sharply from the COLI in several ways by, for example, justifying a Laspeyres-type index formula.

The conference on Price Index Concepts and Measurement held in Vancouver in June 2004 provided an opportunity to review the state of understanding of the issues raised by the NRC panel. In this introduction we

W. Erwin Diewert is a professor of economics at the University of British Columbia and a research associate of the National Bureau of Economic Research. John Greenlees is a research economist in the Division of Price and Index Number Research at the Bureau of Labor Statistics. Charles Hulten is a professor of economics at the University of Maryland, chairman of the executive committee of the Conference on Research in Income and Wealth, and a research associate of the National Bureau of Economic Research.

The authors thank Susanto Basu, Dennis Fixler, Alice Nakamura, Mick Silver, Christina Wang, and two anonymous reviewers for their helpful comments.

1. See Schultze and Mackie (2002).

2. See Stigler (1961).

3. See Boskin et al. (1996). 
provide a brief overview of the papers presented on those issues, in the context of three fundamental topics - the COLI concept, quality change and new goods, and index scope - which have been central issues in almost all previous reviews of the CPI. We use these topics to organize the discussion of the papers, which appear in the conference volume as chapters 1 through 12. We conclude our overview with a description of the new international manuals on price index construction and with a list of important issues remaining for further research.

\section{The Cost-of-Living Concept}

The most easily recognized distinction between the CPI and a COLI is the fact that the CPI is constructed in part using a Laspeyres-type fixed weight index formula that does not reflect the potential for consumer substitution in response to relative price changes. ${ }^{4}$ The role of the COLI concept and its relation to fixed-weight indexes have been central to the debate over the CPI for more than four decades. Support for the COLI concept was one of the broad themes of the Stigler Committee report, which was prepared for the U.S. Government by the National Bureau of Economic Research. The report stated that "A constant-utility index is the appropriate index for the main purposes for which the Consumer Price Index is used" and followed with a series of recommendations designed "to modify the CPI in the direction of a welfare index." 5

The initial reaction of the Bureau of Labor Statistics (BLS) to the Stigler Committee's COLI recommendation was negative, based on the difficulty of estimating a COLI. ${ }^{6}$ However, later statements about the CPI by BLS officials combine references to the COLI as a measurement objective with caveats noting the obstacles to achieving that objective. Using language essentially unchanged since 1984, the current BLS Handbook of Methods states: ${ }^{7}$

A unifying framework for dealing with practical questions that arise in construction of the CPI is provided by the concept of the cost-of-living (COL) index ... However, the concept is difficult to implement operationally because it holds the standard of living constant, and the living standard must be estimated in some way.

The CPI uses a fixed market basket to hold the base-period living standard constant ... The CPI provides an approximation to a COL index as a measure of consumption costs.

4. The new international Consumer Price Index Manual notes that the usual formula employed by statistical agencies should be termed more precisely a Lowe (1823) index, since the reference periods for the base period quantities and base period prices typically do not coincide as they should in order for an index to be a true Laspeyres index; see ILO et al. (2004, 270-74). The COLI theory has been developed by Pollak (1989), Diewert $(1976,2001,2002)$ and others.

5. Stigler (1961, 52-55).

6. Some of the following discussion is taken from Greenlees (2001).

7. Bureau of Labor Statistics $(1997,170)$. 
The Boskin Commission strongly advocated the COLI framework. Its first and fundamental recommendation was that the BLS should adopt the COLI objective, and it also urged the BLS to employ formulas to approximate a COLI as closely as possible. Subsequently, statements by the BLS were somewhat more explicit in indicating the Bureau's acceptance of the costof-living objective.

In contrast to the Stigler Committee, the Boskin Commission, and the BLS, the NRC report did not advocate the COLI as the sole appropriate basis for construction of the CPI. ${ }^{8}$ As previously noted, the NRC panel provided renewed support for the Laspeyres view of price indexing as an alternative to the COLI framework by proposing the COGI, which they defined as "the change in expenditures required by a household to purchase a fixed-weight basket of goods and services when prices change between some initial reference period and a subsequent comparison period." 9 They argued that neither the COLI nor COGI frameworks alone could handle all of the operational problems associated with the CPI.

This argument is examined by Marshall Reinsdorf and Jack Triplett in chapter 1 of this volume. They provide a detailed history of the evolution of the CPI, and a comprehensive review of the various commissions formed to study it. This review reveals the long-standing nature of many CPI issues that are still controversial today. In addition to giving a detailed summary of the various CPI reviews, Reinsdorf and Triplett present their views on the alternative methodological foundations for a consumer price index and, in particular, they debate the merits of the economic or COLI approach versus the COGI. They also note the political economy dimension of the debate. Finally, Reinsdorf and Triplett also contrast the COLI approach to the test or axiomatic approach to the CPI. They argue that the COLI approach to CPI index construction is superior to either the COGI or test approaches, but note that the test approach can be useful on occasion as a supplement to the economic approach to index construction.

Many of the chapters in this volume apply the theory underlying the COLI framework to address difficult measurement issues, issues for which the fixed-weight, fixed basket COGI approach often is silent (for example, the treatment of quality change and the new goods problem). On the other hand, few statistical agencies around the world have accepted the COLI con-

8. At higher levels of aggregation, the Boskin Commission recommended the use of a superlative index number formula and at the lowest level of aggregation (the elementary level), endorsed the use of a geometric mean of price relatives (the Jevons formula) over an arithmetic mean (the Carli formula). These recommendations were also endorsed by the Consumer Price Index Manual; see ILO et al. (2004). The NRC Panel, however, paid relatively little attention to formula issues, particularly at the elementary level.

9. The panel did not seem to object to the use of the Jevons formula at the elementary level of aggregation (see Schultze and Mackie $(2002,279)$. At higher levels of aggregation, the panel was split between COLI and COGI proponents, with COLI proponents favoring the use of a superlative formula while COGI proponents favored a Laspeyres or Lowe type index (see Schultze and Mackie [2002, 1 and 73]). 
ceptual objective. Those agencies, nevertheless, have often employed measurement techniques - such as adjustments for quality differences between products, and frequent updating of product samples and weights - that are consistent with COLI theory. This ambiguity is mirrored in the NRC panel, which could not agree on the COLI-COGI issue but achieved unanimity on all the specific recommendations in its report.

\section{Quality Adjustment and Hedonic Indexes}

Quality adjustment long has been recognized as the most important and difficult issue in the construction of price indexes. In recent decades, hedonic models increasingly have been seen as the preferred tool for solving the quality adjustment problem. The Stigler Committee led the way in this regard, with Zvi Griliches' (1971) path-breaking paper on hedonic models for automobiles as a supporting staff paper. That committee stated, "This method of estimating quality change deserves extensive exploration and application." 10

In the Boskin Report, issues in quality adjustment played a prominent role because the Boskin Commission attributed much of their estimated upward bias in the CPI to the index's failure to adequately deal with improvements in product quality over time. The commission members believed that the BLS should be more aggressive in making quality adjustments, but while they considered hedonics to be a valuable tool, an expansion in hedonic modeling was not one of the specific recommendations in the Boskin Report.

The NRC panel devoted considerable effort to explaining how quality adjustment fits within the COLI and COGI contexts. It also made eight recommendations concerning hedonic methods, some of which have been controversial. Although the panel agreed that "Hedonics currently offers the most promising technique for explicitly adjusting observed prices to account for changing product quality," they also recommended that the BLS should be cautious in further expanding the use of hedonically adjusted price change estimates into the CPI (Recommendation 4-3). ${ }^{11}$ Other recommendations involved the types of hedonic model and index that the NRC panel considered most appropriate and promising. For example, the hedonic approach currently used by the BLS is termed by the panel the "indirect method," because regression coefficients are not used directly in index calculation (instead, individual coefficients associated with quality variables are

10. Stigler $(1961,36)$.

11. Schultze and Mackie $(2002,122)$. Hedonic models were employed in the CPI shelter indexes (to adjust for aging of the rent sample) beginning in the 1980s, and in the apparel indexes beginning in the early 1990s. Between 1998 and 2000, however, the BLS extended the CPI's use of hedonic quality adjustment to computers, televisions, and several other products. Recommendation 4-3 was made in that context. See, for example, Abraham, Greenlees, and Moulton $(1998,31)$, for the BLS view with respect to this issue. 
used to adjust the price differences between disappearing product versions and the models that replace them in the CPI sample). The NRC panel recommends that, while the BLS should continue to study the indirect method, it should also experiment with the "direct characteristics method," in which the index change between two periods is computed using separate hedonic functions estimated for each period. The panel recommends against the approach of estimating index change from the coefficient on a time dummy in a pooled regression.

Highlighting the importance and timeliness of these concerns, three chapters in this volume explore how hedonic methods can be used to develop more accurate price indexes. In chapter 2, Robert Gordon compares hedonic and matched-model indexes for apparel prices in the United States using Sears catalogue data over the period 1914 to 1993, and compares the resulting indexes with the corresponding BLS apparel index over the same period. Gordon finds that the Sears matched-model indexes do not exhibit a consistent negative or positive drift relative to their BLS CPI counterparts. However, he also finds that the hedonic price index for women's apparel always increases more rapidly than the corresponding matched-model index. Gordon sums up his results as follows:

To the extent that the Sears hedonic and matched model indexes are based on the same data, so that systematic differences between catalog market shares and pricing policies are not relevant, the results provided here may offer a nice complement to past research on computer prices, which also found that price changes were contemporaneous with model changes. Just as hedonic price indexes for computers almost always drop faster than matched model indexes for computers, we have found the opposite relationship for apparel prices, although presumably for the same reason.

Thus, new computers come into the marketplace at lower prices once they are adjusted for quality changes, whereas items of apparel (a fashion good) come in at a higher price once they are adjusted for quality change. Gordon interprets his new results as casting some light on what he calls the "Hulten paradox," which he explains as follows:

In an important and influential example, Nordhaus (1997) speculated that, when plausible rates of upward price index bias are extrapolated backwards for two centuries, the increase in real wages from 1800 to 1992, which in the official data is by a factor of 13 to 18 , might have been by a factor of 40 with a low estimate of price index bias ( 0.5 percent per year) or by a factor of 190 with a higher estimate of bias (1.4 percent per year).

In commenting on the Nordhaus results, Hulten (1997) notes that these extrapolations imply an implausibly low real income for U.S. families in 1800. Gordon suggests that this implies that the large Nordhaus upward bias must have been smaller or perhaps even negative at some point in the past, 
and that his own results for downward bias in apparel should be interpreted in light of this possibility.

In chapter 3, Robert Feenstra and Christopher Knittel suggest a new reason why conventional hedonic methods may overstate the price decline of personal computers. They model computers as a durable good and assume that as software changes over time, this influences the efficiency of a computer. Anticipating future increases in software, purchasers may "overbuy" characteristics, in the sense that the purchased bundle of characteristics is not fully utilized in the first months or year that a computer is owned. If this is the case, Feenstra and Knittel argue that hedonic procedures do not provide valid bounds on the true price of computer services at the time the machine is purchased with the concurrent level of software.

The authors develop a theoretical model along these lines, estimate it econometrically, and obtain results that in some cases differ sharply from the hedonic price index constructed with BLS methods. Over the first half of their 1997 to 2001 study period, the hedonic price index declines at an average annual rate of 51 percent, compared to rates of decline of 14 percent and 38 percent for the two indexes based on the authors' production function approach. This overstatement of the fall in computer prices is largely reversed in the second half of their study period, in which the hedonic index falls much more slowly than the production function indexes. Another important result in the Feenstra and Knittel chapter is the establishment of useful bounds on a nonseparable hedonic price index for computer services. The usual theory for a hedonic price index is based on a separability assumption; that is, the constant quality price of a model depends only on the characteristics of the model and not on what quantities of other inputs or outputs that purchasers are using. ${ }^{12}$ However, Feenstra and Knittel develop a model in which the production function for the services of a personal computer depends not only on its vector of characteristics but also on a vector of other (complementary) inputs, and they develop bounds on a constant quality price index that do not depend on being able to observe the vector of complementary inputs. This is an important methodological innovation.

Chapter 4, by W. Erwin Diewert, Saeed Heravi, and Mick Silver, deals with the "direct characteristics method" approach mentioned previously, in which the index change between two periods is computed using separate hedonic functions estimated for each period. The authors compare this method (which they call the "hedonic imputation method") to the usual time dummy approach to hedonic regressions, and derive the exact conditions under which the two approaches to hedonic regressions will give the same

12. See Diewert (2003) for an outline of the usual separable approach to hedonic price indexes. 
results. They consider both weighted and unweighted hedonic regressions and find exact algebraic expressions that explain the difference between the hedonic imputation and time dummy hedonic regression models.

\section{New Goods and New Outlets}

The arrival of new goods in the marketplace poses difficult problems for price measurement. These problems can be addressed from two operational perspectives, although they reflect the same conceptual issue. One perspective is the need for statistical agencies to incorporate these goods into their samples in as timely a fashion as possible. On this first point there seems to be little disagreement, and the only issues surround the expense and operational difficulties of selecting and employing timely samples. The other problem is to incorporate the new goods in a way that reflects the welfare gains arising from the innovations embodied in the new types of products or in the new methods of distributing these goods. ${ }^{13}$

The U.S. CPI, unlike most CPIs around the world, accepts the COLI framework and, in principle, would adjust for the gain in consumer surplus achieved when new goods expand the consumer choice set (or the welfare loss when goods disappear). At this time it is largely a theoretical point, however, because the BLS has argued that the techniques for estimating consumer surplus gains - notably those proposed by Jerry Hausman (1997, 1999) _ “. . . are in their infancy, and may never be adaptable for implementation in a large, ongoing price measurement program like the CPI." 14 This position is consistent with another somewhat controversial Conclusion 5-1 of the NRC panel, that virtual price reductions associated with the introduction of new goods should not be imputed for use in the CPI.

The panel's conclusion is controversial because all economists would agree that if the appearance of new goods makes it possible for some, if not all, consumers to reduce the expenditure required to achieve a given utility level, a properly designed COLI should reflect this fall. Moreover, from a conceptual point of view, the idea of reflecting the welfare gains from the introduction of a distinctly new good like e-mail is no different from the idea of reflecting the welfare gains from the introduction of a slightly enhanced model of television, which the CPI already attempts to do through its quality adjustment processes. Indeed, the boundary between quality adjustment and new goods can depend on the level of aggregation: at the level of "personal motor vehicles," the advent of the sport utility vehicle may be treated as an enhancement in quality through an increase in quantity of

13. Hicks $(1940,114)$ developed a suitable methodology and Hausman $(1997,1999)$ implemented this methodology. For some potentially useful techniques that could be used to quantify estimates of bias in a COLI, see Diewert (1998) and Hausman (2003).

14. Abraham, Greenlees, and Moulton (1998, 33). 
some hedonic characteristics, but when viewed from the standpoint of the market for transportation services, it appears as a new good. The NRC panel's qualified endorsement of price hedonics but failure to endorse a new goods adjustment are difficult to reconcile, highlighting the difficult and controversial nature of the new goods issue. Unfortunately, it appears that the importance of the issue will only increase with time. In today's economy the rate of introduction of wholly new goods is accelerating, breaking down the barriers between product categories and presenting many new challenges for calculation of a COLI-based CPI.

The new goods controversy is, to some extent, a debate over issues of implementation. The BLS and the NRC panel are in agreement that there are reliable operational (e.g., price hedonic) methods for comparing the effectiveness of different models in providing the services of a television or computer. They also agree with each other (although not with all economists) that similarly reliable methods do not yet exist for comparing the effectiveness of new methods of interpersonal communication-such as cellular telephones, text messages, and e-mail—or for valuing the benefits to consumers of a wider array of product choices in markets like breakfast cereal.

The phenomenon of new outlet types parallels that of new products. In chapter 5, Jerry Hausman and Ephraim Leibtag focus on the fact that the CPI does not compare the prices charged for the same items at different outlets. In effect, the BLS assumes that any price differences can be explained by differences in outlet characteristics valued by consumers, such as locational convenience or customer service. It therefore may fail to incorporate the gains to consumers from the continuing growth in sales at Wal-Mart and other low-price, high-volume superstores. The authors employ the A.C. Nielsen Homescan consumer panel data to identify the price differentials for twenty food product categories between supercenters, mass merchandisers, and club stores (SMCs) and other outlets. These differentials, combined with the SMCs' increasing market share, lead Hausman and Leibtag to conclude that CPI food at home inflation is too high by about 0.32 to 0.42 percentage points annually.

\section{Index Scope and the Conditional COLI}

The NRC panel gave considerable attention to the question of the appropriate scope of a COLI. Conceptually, a COLI can be unconditional, in the sense that it reflects changes in life expectancy, future income, air quality, indeed, all other factors affecting consumer welfare beyond the direct consumption of goods and services. These indirect factors are hard to capture in a price index and make the index hard to interpret when they are captured (do we want the CPI to show a change during a period of constant prices because air quality has changed?). As an alternative, a variant of the COLI 
can be defined that is conditional on some or all of those "environmental" factors. ${ }^{15}$

This distinction was not a major emphasis in the Stigler or Boskin reports, although the latter did include recommendations for research on quality of life factors, crime, and other factors. In contrast, Conclusions 2-1, 2-2, and 3-1 of the NRC panel report argued that the unconditional COLI is unsuitable for the CPI, and that within either the COLI or COGI framework the appropriate index concept should be restricted to private goods and services. Like the Boskin Commission, the NRC panel did also recommend that the BLS undertake research on more comprehensive price measures on an experimental basis, jointly with other federal statistical agencies.

As the panel noted, the U.S. CPI is designed to approximate a conditional COLI. The conceptual view taken by the BLS was laid out by Robert Gillingham (1974), based on the theory of conditional COLI subindexes as presented by Robert Pollak. ${ }^{16}$ It should be noted, however, that even having established that the CPI is designed to approximate the conditional COLI, there still may be problems or ambiguities in specifying the precise nature of what is held constant as a conditioning variable.

Chapters 6 through 11 in this volume examine (directly or indirectly) issues concerning the scope of a COLI. Two of these involve measurement of the cost of financial services. The U.S. CPI excludes most financial services because it regards these services as costs of moving consumption from one period to another period and hence regards the costs as being out of scope. However, in chapter 6, Dennis Fixler makes a case for including these transactions costs in a CPI, and he presents a user cost model for the treatment of financial services, in which the prices of loan and deposit services are represented by the difference between the corresponding interest rates and a risk-free reference rate. He constructs various alternative household financial services price indexes using quarterly data from the Bureau of Economic Analysis (BEA) over the period 1987 to 2003. Two controversial components in Fixler's experimental indexes are (a) the reference rate(s) of return used to calculate the nominal user costs of household bank deposits and household bank loans and (b) the deflator(s) used to convert nominal financial service flows into real flows.

In chapter 7, Christina Wang, Susanto Basu, and John Fernald present a general equilibrium approach to measuring bank output, an approach that turns out to be quite different from Fixler's in some important respects. In contrast to deflating nominal asset holdings by a user cost price index,

15. Schultze and Mackie (2002, 86-87). Diewert (2001) developed the theory of the conditional COLI in some detail and suggested that if the chain principle is used, then an aggregate conditional COLI can usually be reasonably well approximated by an appropriate Fisher ideal index. Caves, Christensen, and Diewert (1982,1409-11) also have a useful exact result for a conditional COLI for a single consumer who has translog conditional preferences.

16. Pollak (1989), chapter 2. 
Wang, Basu, and Fernald suggest that direct measures of the services rendered by consuming financial services be constructed and then the nominal service flows deflated by these direct measures. In resolving this controversy, the devil is in the details; that is, a detailed model developed by user cost advocates such as Fixler can be compared to the detailed model developed by Wang and her coworkers, and users can decide which framework seems more reasonable.

Another scope issue has to do with the pricing of medical services. One chapter of the NRC Report and three specific recommendations are devoted to the problem of medical care pricing. The Stigler Committee did not specifically address medical care, and the Boskin Commission discussed it only in the context of estimating upward bias in the CPI medical care indexes and as part of its broad recommendation to expand the CPI framework. We include medical care in this section because it highlights the issue of what prices should be used in the CPI. Traditionally, the U.S. CPI collected prices on the goods and services used as inputs to health care: prescription drugs, office visits, surgical procedures, and so on. This would appear to be consistent with a COGI framework. During the 1990s, a shift was made in the CPI Hospital Services component to pricing patterns of treatment for specific conditions, rather than the individual inputs. Ideally, a COLI would be based on pricing outcomes, with "health" as the argument in the consumer's utility function. Chapter 8 by Xue Song, William Marder, Robert Houchens, Jonathan Conklin, and Ralph Bradley looks at some of the issues involved in implementing such an approach. Comparing disease-based indexes to indexes simulated using current CPI methodology for New York, Philadelphia, and Boston, Song and colleagues suggest that the diseasebased indexes may be superior, but that given the large standard errors the differences among indexes were not significantly different in many cases.

Extension of price measurement to the difficult area of governmentprovided education services is the subject of chapter 9, by Barbara Fraumeni, Marshall Reinsdorf, Brooks Robinson, and Matthew Williams. This market presents the usual problems of services price measurement; in addition, education services are provided without explicit charge to consumers, their production involves significant nonmarket inputs, the contribution of providers is difficult to isolate, and the benefits of education are complex and difficult to value.

The authors begin their chapter with a careful review of the literature on measuring education output in the United States and elsewhere. They then develop and compare alternative quality-adjusted and unadjusted measures of the price and real output of U.S. primary and secondary education services, using three dimensions of quality: teaching staff composition, the pupil-teacher ratio, and the high-school dropout rate. For their entire 1980 to 2001 period of study, the use of their preferred method of quality adjust- 
ment raises the estimated annual growth rate of real output by 0.18 percent. This study is part of the ongoing efforts by the BEA to improve the valuation of government output in the U.S. national accounts.

Kam Yu's chapter 10 presents a novel approach to pricing gambling services, using data on the Canadian lottery system. Like Statistics Canada and most statistical agencies, the BLS excludes gambling from the scope of the CPI, partly because it is difficult to determine exactly what is the appropriate pricing concept and partly because the complexity of making adjustments for "quality" improvements seems to be incredibly complex. ${ }^{17}$ The quality adjustment problem arises from the fact that, if a lottery increases the odds of winning the lottery, then it appears that a positive increase in "quality" has occurred. Classical expected utility theory could be applied to provide answers to this quality adjustment problem but, as Yu notes, this theory does not work satisfactorily in the gambling context. Yu's chapter does specify an appropriate concept but its theoretical complexity and empirical volatility may prevent statistical agencies from adopting his concept.

Chapter 11 by T. Peter Hill discusses another aspect of the CPI scope problem - the implications of expanding coverage of the CPI to include nonmarket household production. Hill notes that a major problem with the traditional theory of the CPI is that households do not directly consume most of the goods and services recorded under consumer expenditures. Estimates for the United States in 1992 suggest that only 12 percent of the goods and services recorded as final consumer expenditures are directly consumed by households without further processing.

Meals prepared at home are a case in point. The household purchases groceries and combines them with household labor and capital to produce the meals on the table. By implication, the CPI is not an index of the cost of consumption (the usual interpretation), but is instead largely a price index of the intermediate goods used by households to produce consumption goods.

Hill cites estimates by Landefeld and McCulla (2000) that suggest that the inclusion of household production in the U.S. national accounts increases GDP by 43 percent in 1946 and by 24 percent in 1997 . However, he also notes that the inclusion of household production in the CPI will lead to many imputations in the resulting index and hence

a price index that is calculated mainly from imputed prices would not be acceptable to most users. A CPI is key statistic for policy purposes which can have important financial implications as it is widely used for indexation purposes. It has to be objective, transparent, reliable and credible.

Hill does not speculate whether the CPI is a reasonable proxy for the "true" price index of household consumption, nor whether "policy and indexation

17. In the production accounts of most countries, the output of the lottery sector is measured by the inputs used. 
purposes" are better served by the "true" index of the CPI, but he does raise the following question: if a cost-of-living adjustment is to be based on the compensating variations of utility theory (a point debated by the NRC panel), the implication of this chapter is that the CPI is on rather shaky theoretical ground.

The last chapter in this volume deals with issues of durable goods and rental equivalence. The treatment of durable goods, in particular of residential housing, was a major issue in the Stigler Report, and statistical agencies around the world continue to differ widely on their treatment of homeownership costs. The Stigler Committee argued that because a true cost-ofliving index or "constant-utility index" is the appropriate index for the CPI, and because the welfare of consumers depends upon the flow of services from durable goods, not upon the stocks acquired in a given period, successful development of a rental equivalence series would offer the basis for an improved CPI. Agencies that reject the COLI framework either exclude homeownership from the CPI or measure homeowner costs using prices of housing assets; agencies like the BLS that accept the COLI tend to employ the rental equivalence approach.

The problem of homeownership is one aspect of the broader household consumption problem. Both the Boskin Commission and the NRC panel accepted the Stigler Committee's view that a flow-of-services measure of consumption is the conceptually correct concept for homeownership. The NRC report concludes that the prices of durable goods ideally should be converted to user costs before being aggregated into a price index, whether a basket price index (COGI) or a COLI. ${ }^{18}$ Recognizing a wide range of conceptual and practical difficulties, however, the panel did not examine durable goods pricing in detail. ${ }^{19}$

In chapter 12, Erwin Diewert provides a detailed review of alternative treatments of homeownership in a CPI, discussing the advantages and disadvantages of several approaches to measuring homeowner costs: the acquisition price of housing units, per-period homeowner spending for mortgage interest and other periodic payments, user cost, and rental equivalence. The latter two techniques are alternative flow-of-services approaches. Diewert notes that a major difficulty associated with forming any housing price index is that units are unique and they also depreciate (or are augmented by renovations) over time, making it difficult to construct price indexes using a matched-model methodology, and discusses various methods for overcoming this difficulty. He suggests that the "right" price for housing services is the maximum of its rental equivalence price and its user cost. 


\section{Discussants' Comments}

Our brief synopsis of the chapters has not included a summary of the discussant comments. We highly recommend that they be read jointly with the corresponding chapter, since many offer critical comments and alternative views.

\section{The New CPI and PPI Manuals}

Shortly after the NRC panel report appeared, two new international manuals on price measurement problems appeared in 2004: the Consumer Price Index Manual: Theory and Practice, edited by T. Peter Hill, and the Producer Price Index Manual: Theory and Practice, edited by Paul Armknecht; see the International Labour Organization (ILO 2004) and the International Monetary Fund (IMF 2004), respectively. These new international agency manuals replaced an older ILO CPI Manual that was published in 1989 and an even older United Nations (UN) Producer Price Index (PPI) Manual that was published in 1979. The sponsoring international agencies for these two manuals were Eurostat, the ILO, the IMF, the Organization for Economic Cooperation and Development (OECD), the World Bank, and the UN.

The new price manuals were quite different from previous international manuals, which tended to prescribe "best practices" but did not have much discussion on what led up to the chosen procedures. In contrast, the new manuals were much less prescriptive and instead tried to present the alternatives in a more or less unbiased way. However, this new less dogmatic approach actually proved to be very productive. In particular, statistical agencies on both sides of the Atlantic were able to agree that no matter what approach one took to index number theory, a superlative index seemed to be a reasonable target index to aim for in practice. ${ }^{20}$ Thus, the new manuals tried to present reasonable principles rather than specific rules. The two manuals also tried to harmonize their contents so that they would not contradict each other.

Some of the important topics that these new manuals considered in more detail than the older manuals were:

- Quality adjustment methods, including extensive discussions about hedonic regression methods.

- Approaches to seasonal adjustment.

20. European price statisticians tended to favor the fixed basket, test, or stochastic approaches to index number theory while North American price statisticians tended to favor the economic approach. The new Manuals showed that all of these approaches led to either the Fisher ideal, the Törnqvist-Theil, or the Walsh indexes and since these indexes closely approximated each other numerically, it was not worth arguing over which approach was the "right" one. 
- A detailed treatment of the Lowe index. ${ }^{21}$

- The usefulness of producing indexes for different classes of users; that is, statistical agencies should produce not only "standard" indexes but also "analytical" indexes that meet the needs of specialized users.

Following on the success of these two new manuals, the international agencies who are concerned with economic price and quantity measurement problems are sponsoring a new effort: an XMPI (Export Import Price Index) Manual, with the IMF taking the lead in organizing and publishing the manual.

\section{Outstanding Issues in the Construction of a Consumer Price Index}

We conclude with a few of the outstanding issues in the construction of a $\mathrm{CPI}$ that need to be resolved. Most of the questions in the partial list below were raised by the chapters in this volume. Answers will probably not be forthcoming in the immediate future, but these are important questions that require either further research or discussion that would lead to a consensus on the issues:

- How should the value of service-sector outputs like banking, educational, medical, gambling, and insurance services be measured, and can they reliably be separated into price and quantity components?

- How can satellite accounts for the household production sector be constructed in current and constant prices?

- How should the welfare gains from new goods be incorporated into the price index? How does the classical "new goods" problem differ from the price hedonic problem of measuring quality change in a continuum of "improved" goods?

- If scanner data are being used at the elementary (lower) level of the $\mathrm{CPI}$, then how much time aggregation is desirable as unit values are aggregated over time? One could also ask the same question with respect to aggregation over outlets.

- What is the "right" index number formula to use at the elementary (lower) level of index aggregation if weight information is or is not available?

- How can we deal with outlet bias in an objective manner?

- What is the "best" way for a statistical agency to employ hedonic regressions in official CPIs, and should the regressions be run with or without weights?

21. The Lowe price index is one that uses (annual) weights from one reference period and base period (monthly) prices from another reference period, as well as current period (monthly) prices, which is in fact how most CPIs are constructed. Somewhat surprisingly, the academic literature on index numbers never considered the properties of such an index. 
- Should price measurement be harmonized with the System of National Accounts or should it proceed in a more or less independent manner?

- What is the "right" concept to price the services of owner-occupied housing?

\section{References}

Abraham, K. G., J. S. Greenlees, and B. R. Moulton. 1998. Working to improve the Consumer Price Index. Journal of Economic Perspectives 12 (1): 27-36.

Boskin (Chair), M. J., E. R. Dulberger, R. J. Gordon, Z. Griliches, and D. W. Jorgenson. 1996. Final report of the Commission to Study the Consumer Price Index. U.S. Senate, Committee on Finance, Washington DC: GPO.

Bureau of Labor Statistics. 1997. BLS handbook of methods, Bulletin 2490. Washington, DC: GPO.

Caves, D. W., L. R. Christensen, and W. E. Diewert. 1982. The economic theory of index numbers and the measurement of input, output, and productivity, Econometrica 50 (6): 1393-1414.

Diewert, W. E. 1976. Exact and superlative index numbers. Journal of Econometrics 4 (2): $114-45$.

. 1998. Index number issues in the Consumer Price Index. The Journal of Economic Perspectives 12 (1): 47-58.

2001. The Consumer Price Index and index number purpose. Journal of Economic and Social Measurement 27: 167-248.

2002. Harmonized indexes of consumer prices: Their conceptual foundations. Swiss Journal of Economics and Statistics 138 (4): 547-637.

2003. Hedonic regressions: A consumer theory approach. In Scanner data and price indexes, Studies in Income and Wealth vol. 64, ed. R. C. Feenstra and M. D. Shapiro. 317-47. Chicago: University of Chicago Press.

Gillingham, R. 1974. A conceptual framework for the Consumer Price Index. Proceedings of the American Statistical Association 1974 Business and Economic Statistics Section. Washington, DC: American Statistical Association.

Greenlees, J. S. 2001. The U.S. CPI and the cost-of-living objective. Paper prepared for the Joint ECE/ILO Meeting on Consumer Price Indices. 2 November, Geneva, Switzerland.

Griliches, Z. 1971. Hedonic price indexes for automobiles: An econometric analysis of quality change. In Price indexes and quality change, ed. Zvi Griliches, 55-87. Cambridge, MA: Harvard University Press.

Hausman, J. A. 1997. Valuation of new goods under perfect and imperfect competition. In The economics of new goods, Studies in Income and Wealth 58, ed. T. F. Bresnahan and R. J. Gordon, 209-37. Chicago: University of Chicago Press. . 1999. Cellular telephone, new products, and the CPI. Journal of Business and Economic Statistics 17 (2): 188-94.

2003. Sources of bias and solutions to bias in the CPI. The Journal of Economic Perspectives 17 (1): 23-44.

Hicks, J. R. 1940. On the valuation of the social income. Economica 7 (February): 105-24.

Hulten, C. R. 1997. Comment. In The economics of new goods, Studies in Income 
and Wealth vol. 58, ed. T. F. Bresnahan and R. J. Gordon, 66-70. Chicago: University of Chicago Press.

International Labour Organization (ILO), Eurostat, IMF, OECD, World Bank, and the UN. 2004. Consumer Price Index manual: Theory and practice, ed. Peter Hill. Geneva: International Labour Organization. Available at: http://www.ilo.org/ public/english/bureau/stat/guides/cpi/index.htm.

Landefeld, J. S., and S. H. McCulla. 2000. Accounting for nonmarket household production within a national accounts framework. Review of Income and Wealth 46 (3): 289-307.

Lowe, J. 1823. The present state of England in regard to agriculture, trade and finance, 2nd edition. London: Longman, Hurst, Rees, Orme, and Brown.

Nordhaus, W. D. 1997. Do real output and real wage measures capture reality? The history of lighting suggests not. In The economics of new goods, Studies in Income and Wealth vol. 58, ed. T. F. Bresnahan and R. J. Gordon, 29-66. Chicago: University of Chicago Press.

Pollak, R. A. 1989. The theory of the cost-of-living index. New York: Oxford University Press.

Schultze, C. I., and C. Mackie, eds. 2002. At what price? Conceptualizing and measuring cost-of-living and price indexes. Committee on National Statistics, Washington DC: National Academy Press.

Stigler, G. J. (Chairman). 1961. The price statistics of the federal government. New York: National Bureau of Economic Research. 